\title{
GENRE PARAMETERS OF STRATEGY AS A DOCUMENT OF LONG-TERM PLANNING
}

\author{
Aleksandra S. Bystrova \\ Volgograd State University, Volgograd, Russian Federation
}

\begin{abstract}
The article characterizes the role of business communication in modern society and, in particular, the role of strategic planning documents, their impact on the public consciousness. The analysis of the strategy identifies the function of the document, composition and speech peculiarities of the text.

The author demonstrates the possibility of using the genre approach to the description of compositecontent structure of the document text and using a model of the speech genre as a linguistic technology of its analysis. Using the example of genre of strategy, the author discusses the features and linguistic means of representing the basic genre elements in the document text. These elements compose the model of speech genre and reflect the interaction of extralinguistic factors and linguistic material: communicative purpose, author's image, addressee's image, image of the past, vision of the future, type of dictum content, linguistic embodiment. It is proved that the communicative purpose, associated with the idea of the document's author, and the image of the future are fundamental components of the genre of strategy.

Based on the complex of considered parameters in their interaction, especially their verbal expression, the strategy is defined as the genre of the document of long-term planning, which performs an informative and appellative function; it is noted that wide representation and the variety of language means of expressing the vision of the future in combination with the explicit intentions of the strategy's author determine the futurality of the text.

Key words: document, document text, the document of strategic planning, speech genre, forcing function, speech organization, futurality.

Citation. Bystrova A.S. Genre Parameters of Strategy as a Document of Long-Term Planning. Vestnik Volgogradskogo gosudarstvennogo universiteta. Seriya 2, Yazykoznanie [Science Journal of Volgograd State University. Linguistics], 2017, vol. 16, no. 3, pp. 199-206. (in Russian). DOI: https://doi.org/10.15688/jvolsu2.2017.3.20
\end{abstract}

\section{ЖАНРОВЫЕ ПАРАМЕТРЫ СТРАТЕГИИ КАК ДОКУМЕНТА ДОЛГОСРОЧНОГО ПЛАНИРОВАНИЯ}

\author{
Александра Сергеевна Быстрова \\ Волгоградский государственный университет, г. Волгоград, Российская Федерация
}

\begin{abstract}
Аннотация. В статье характеризуется роль деловой коммуникации в современном социуме, ее влияние на общественное сознание. Показана возможность применения жанрового подхода к описанию композиционно-содержательной структуры документного текста и эффективность использования модели речевого жанра как лингвистической технологии его анализа. На примере жанра стратегии рассматриваются особенности и языковые средства репрезентации в документном тексте основных жанровых элементов, которые составляют модель речевого жанра и отражают взаимодействие экстралингвистических факторов и языкового материала: коммуникативная цель, образ автора, образ адресата, образ прошлого, образ будущего, тип диктумного содержания, языковое воплощение. Установлено, что коммуникативная цель, связанная с замыслом авторов документа, и образ будущего являются основополагающими компонентами жанра стратегии.

На основании совокупности рассмотренных параметров в их взаимодействии, с учетом особенностей их речевого выражения стратегия определяется в статье как жанр документа долгосрочного (стратегическо-
\end{abstract}


го) планирования, который выполняет информативную и воздействующую функции; отмечается, что широкая представленность и разнообразие языковых средств выражения образа будущего в сочетании с эксплицированными интенциями автора стратегии как документа определяют футуральность ее текста.

Ключевые слова: документ, документный текст, документ стратегического планирования, речевой жанр, функция воздействия, речевая организация текста, футуральность.

Цитирование. Быстрова А. С. Жанровые параметры стратегии как документа долгосрочного планирования // Вестник Волгоградского государственного университета. Серия 2, Языкознание. - 2017. - Т. 16, № 3. C. 199-206. - DOI: https://doi.org/10.15688/jvolsu2.2017.3.20

1

Усиление роли деловой коммуникации в современном обществе определило актуальность исследования документов различных функциональных сфер, особенностей композиционно-содержательной и речевой структуры их текстов, составляющих объект документной лингвистики как нового вектора науки о языке.

В последние годы появились работы, посвященные управленческим документам [Кузнецова, 2002; Ларин, 2001; Ларьков, 2006], документам сферы права [Кушнерук, 2010], государственного управления образованием [Белоконева, 2011], науки [Краснова, 2009], медицины [Ромашова, 2014], связей с общественностью [Плигина, 2012], волонтерских объединений [Саидгасанова, 2014] и др. Полученные результаты расширили уже имеющиеся сведения о документном тексте, его основных свойствах, видовом разнообразии. Тем не менее остаются неизученными еще многие документные системы, в частности документы стратегического планирования, которые играют важную роль в жизни социума, способствуя «пониманию всеми участниками процесса стратегического управления логики реализуемых мер, их ресурсного сопровождения и собственного значения в общей деятельности» [О гармонизации документов..., 2015, с. 3]. Согласно Федеральному закону от 28 июня 2014 г. № 172-Ф3 «О стратегическом планировании в Российской Федерации» к таким документам относятся прогнозы, планы, программы, стратегии (ст. 11).

Обратимся к основному, на наш взгляд, документу данной группы - стратегии. В современном русском языке существительное стратегия представлено как многозначное: «Стратегия [греч. stratēgía] - 1. Высшая область военного искусства - ведение крупных военных операций и войны в целом. C. молниеносного удара. Вопросы стратегии и тактики. Разрабатьвать стратегию сражения. С. партизанской войны. 2. Искусство руководства общественной, политической борьбой с целью достижения практических результатов. С. оппозициионной парламентской партии. С. президентских выборов. 3. Искусство планирования какой-л. деятельности (экономической, научной и т. п.) на длительную перспективу. С. научного поиска. 4. Общий план спортивной игры, последовательно реализуемый в ходе этой игры. С. шахматной игрыл» (БТСРЯ, с. 1277). Третье значение слова является наиболее близким к специальному, «документоведческому» термину. Исходя из семантики слова, а также назначения документных текстов данного жанра, мы определяем Стратегию как документ долгосрочного планирования, направленный на информирование адресата и разъяснение сути работы организации, основных перспектив и результатов ее деятельности.

2

Для изучения свойств документа, особенностей речевой организации документного текста важно выявить его жанрово-видовые параметры (в рамках предпринятого исследования по отношению к документу термины «жанр» и «вид» используются как синонимы). Рассмотрим речевую организацию текста стратегии на материале Стратегии Всероссийской общественной организации «Русское географическое общество» (далее Стратегия), утвержденной 6 июля 2012 г. УПравляющим советом Всероссийской общественной организации «Русское географическое общество» (далее - РГО).

Вопрос о жанрах, их релевантных признаках, или параметрах, является одним из 
дискуссионных в науке. Существуют разные подходы к их изучению - традиционный (связанный с исследованием жанров художественной литературы), функциональный, коммуникативно-дискурсивный, когнитивный [Ильинова, 2006, с. 10-11]; предлагаются различные классификации жанров и т. д. [Бабенко, 2004; Гальперин, 2004; Жанровые особенности..., 2016; Качалкин, 1988; Косова, 2015; Ромашова, 2014; Трофимова, 1997, 2013].

Для анализа текста Стратегии мы используем подход, принятый в работах Т.В. Шмелевой [Шмелева, 1997, с. 88-89]. По мнению исследователя, модель речевого жанра состоит из семи конститутивных компонентов - коммуникативной цели, образа автора, образа адресата, образа прошлого, образа будущего, типа диктумного содержания и языкового воплощения жанра. Принципы такого анализа с некоторыми коррективами используются как алгоритм описания документного текста [Белоконева, 2011; Косова, 2012; Краснова, 2009; Ромашова, 2014].

Коммуникативная цель является основополагающим компонентом речевого жанpa, поскольку связана с замыслом автора, его интенциями, которые, как правило, вербализованы в тексте документа.

Так, в тексте рассматриваемого нами документа говорится, что «в основе стратегии развития Русского географического общества - комплексное географическое познание России и мира во всем их многообразии, которое способствует реализаиии творческого потенииала нашей Родины и ее граждан», а ключевой целью Русского географического общества является «консолидащия сил и стремлений российского общества в деле изучения и популяризаиии географии и смежных наук для реализачии творческого потенциала страны и ее граждан» (Стратегия РГО, с. 1).

Существительное консолидация (от глагола консолидировать - «укрепить / укреплять, сплотить / сплачивать для усиления деятельности») обозначает активную деятельность субъекта, предполагающую воздействие на кого-либо (МАС, т. 2, с. 91). Запланированные действия субъектов как задачи документа выражены отглагольными существительными стимулирование, организация участия, популяризачия, сбор, обработка, содействие, привлечение внимания и др.

Сформулированные в документе цель и задачи РГО дают основание считать, что Стратегия выполняет информативную функцию (информирует о направлениях деятельности РГО: исследовательская, информационная, образовательная и просветительская, природоохранная, экспедиции и путешествии, издательская, грантовая, организация и проведение общественных мероприятий, международная), а также функцию воздействия: в тексте документа отмечается важность привлечения сторонников в ряды РГО, расширения круга единомышленников и необходимость объединения граждан, заинтересованных в развитии природоохранной деятельности на территории России (Важнейшая задача РГО - объединить людей, неравнодушных $\kappa$ природе Родины; ...Стимулирование и организачия активного участия общества в природоохранной деятельности; Возрождение и расширение сети единомышленников Русского географического общества за рубежом...; Привлечение молодежи к активному участию в деятельности Русского географического общества).

Эксплицированы и результаты запланированной деятельности, которые соотносятся с целью РГО: Основными результатами деятельности региональных отделений Русского географического общества должны стать: повышение уровня информированности граждан о регионе, в котором они проживают, увеличение числа активных сторонников Русского географического обшества, повышение степени общественного участия в природоохранных мероприятиях и экспедициях.

Автор Стратегии является коллективным: документ подготовлен группой официальных лиц, наделенных определенными полномочиями. В тексте документа автор выражен неодушевленными нарицательными существительными, содержащими в структуре значения сему 'организация': Русское географическое общество (РГО); Общество; Постоянная Природоохранительная комиссия РГО; региональные отделения РГО и т. д.

Адресат документа очень широкий. В тексте Стратегии он выражен нарицатель- 
ными именами существительными, которые называют общественные организации (региональные отделения РГО, общественные и коммерческие организаиии); государственные учреждения (органы власти, образовательные учреждения, исследовательские центры); представителей общественности (активные сторонники РГО, общество, частные лица, СМИ); молодежи (молодые ученые, школьники, студенты, молодежь).

Образы прошлого и будушего для документа связаны со свойством системности: документ всегда принадлежит какой-либо системе документов и связан с другими документами [Косова, 2012, с. 8].

Образ прошлого - это описанные в тексте документа события, которые послужили поводом для его создания, или указание на предшествующие документы, обусловившие появление данного документа [Шмелева, 1990, c. 29]. Этот компонент различает жанры, возникающие как определенная реакция на другие жанры, и «инициальные» или «начинающие общение» жанры [Косова, 2015, с. 74], к которым, на наш взгляд, относится жанр Стратегии.

Для рассматриваемого нами документа образом прошлого является описание ситуации - традиций в деятельности Русского географического общества, реализующих принцип преемственности. В тексте Стратегии РГО это, в частности, выражается следующими речевыми фрагментами: продолжаем путь, пройденный РГО за многолетнюю историю; изучение наследия РГО; с 1845 года, когда было основано РГО; продолжая свои богатые издательские традиции и т. д.

Образ будущего для документа составляет описание событий, которые произойдут, или упоминание в тексте документов, появление которых будет обусловлено данным документом.

В тексте Стратегии РГО образ будущего представлен только как описание событий. Для этого используются:

- глаголы с семантикой планирования (планировать, предполагать, иметь намерения, заявлять) или позитивных изменений (развивать) в форме будущего времени несовершенного вида (Общество будет руко- водствоваться, РГО будет развивать, будет совершенствовать) или настоящего времени (РГО планирует поддержку, РГО предполагает развивать и поддерживать, РГО предполагает развивать и др.);

- отглагольные существительные с семантикой положительного результата, приращения чего-либо, какого-либо свойства: создание основы, комплексное познание, консолидация сил и стремлений, возрождение и расширение сети единомышленников и т. Д.;

- прилагательные, обозначающие длительность и планомерность изменений: РГО открыто для долгосрочного сотрудничества, формирование долгосрочных связей и проектов, устойчивое развитие и др.;

- прилагательные, имеющие сему 'новизна': подготовка новых специалистов, инновационные технологии, новейшие технологии, разработка новых туристических маршрутов и др.;

- прилагательные и существительные, содержащие в значении сему 'молодой': издание работ молодых ученых, осуществление молодежных программ, воссоздание детско-юноческого движения, молодежь, подрастающее поколение, икольники, студенты и др.

Основой диктумного (событийного) содержания жанра Стратегии является разъяснение сути деятельности Русского географического общества.

Описание содержания планируемой деятельности РГО обусловливает использование терминов предметной области документа (природоохранная деятельность, экоэкспедиции, ландшафт, картографические материаль, экотропь и т. д.), а также особое объемно-прагматическое деление текста на микротексты, имеющие однотипную синтаксическую структуру, например: Важнейшая задача РГО - объединить людей, неравнодушных к природе Родины. В основе стратегии развития РГО - комплексное географическое познание России и мира во всем их многообразии, которое способствует реализации творческого потенииала нашей Родинь и ее граждан.

Релевантным признаком речевого жанра является языковое воплощение - параметр, который, по мнению Т.В. Шмелевой, 
лингвистически наиболее важен, так как «прямо выводит речевой жанр в пространство языка с его сложнейшей дифференциацией языковых средств по требованиям речи» [Шмелева, 1997, с. 97]. Это «требование речи» (информативная и воздействующая функции) находит реализацию в языковом воплощении жанра стратегии, которое характеризуется сочетанием в тексте черт документного и публицистического текстов.

Чертой документного текста, обусловленной информативной функцией Стратегии, является использование:

- официонимов: Управляюший совет Всероссийской общественной организации «РГО», Постоянная Природоохранительная комиссия РГО и др.;

- наименований документов и делопроизводственных процессов: протокол, заседание, стандарты регионального управления, Устав РГО, Стратегия развития;

- клишированных словосочетаний: cnoсобствует реализации, активно участвовать, приоритетное направление, всестороннее исследование, утвердить, принять меры и стандартных оборотов - так называемого «речевого наполнения реквизитов»: Стратегия Всероссийской общественной организаиии «РГО», Стратегия утверждена Управляющим советом Всероссийской организачии «РГО», протокол заседания № 5 от 6 июля 2012 г.;

- сложных и сложносокращенных слов: СМИ, РГО, экотропь, экоэкспедиции, «Географгиз»;

- абстрактных имен существительных с суффиксами -ость, -ениј-, -иј-: привлечение, деятельность, стимулирование, формирование, распространение, содействие;

- конструкций с модальностью долженствования: портал должен предоставить, региональное отделение должно стать центром и др.

Чертой публицистического текста, обусловленной функцией воздействия, является использование:

- лексических единиц, выражающих интенсивность проявления признака: лучших достижений отечественной науки, уникальным географическим объектом, важнейшая задача, приумножение объема зна- ний, самые актуальные вопросы, наиболее значимые труды и т. д.;

- общественно-политической лексики: межоднародная и российская общественность; примеры бережного отношения $\kappa$ природе России со стороны граждан, государственных структур и общественных организаций с привлечением различных СМИ; проведение общественных природоохранных мероприятий; система региональных отделений и др.;

- речевых штампов: система мер $u$ шагов, направления деятельности, стратегия развития, потенииал страны и ее граждан, привлечение внимания; продолжают путь, ставит перед собой задачи, приоритетными направлениями являются и др.

3

Совокупность рассмотренных параметров в их взаимодействии, особенности их речевого выражения позволяют определить Стратегию как жанр документа долгосрочного планирования, который выполняет информативную и воздействующую функции. Частотность и разнообразие языковых средств выражения образа будущего в сочетании с эксплицированными как коммуникативная цель интенциями автора обусловливают специфику этого документа - футуральность его текста. Дальнейшее исследование этого свойства как особой категории позволит углубить представления о сходстве и различиях жанров документов, общем и специфическом в реализации жанровых компонентов, о видовой организации документных систем.

\section{СПИСОК ЛИТЕРАТУРЫ}

Бабенко, Л. Г. Лингвистический анализ художественного текста. Теория и практика / Л. Г. Бабенко, Ю. В. Казарин. - М. : Флинта : Наука, 2004. -496 c.

Белоконева, К. А. К проблеме жанрово-стилевой принадлежности документного текста / К. А. Белоконева // Вестник Волгоградского государственного университета. Серия 2, Языкознание. - 2011.№2 (14). - С. 148-153.

Гальперин, И. Р. Текст как объект лингвистического исследования / И. Р. Гальперин. - М. : Едиториал УРСС, 2004. - 144 c. 
Жанровые особенности войсковых грамот середины XVIII в. (по материалам архивного фонда «Михайловский станичный атаман») / О. А. Горбань, Е. Ю. Ильинова, М. В. Косова, Е. М. Шептухина // Известия Уральского федерального университета. Серия 2. Гуманитарные науки. - 2016. - Т. 18, № 4 (157). C. 182-199.-DOI: 10.15826/izv2.2016.18.4.074.

Ильинова, Е. Ю. Когнитивный аспект жанрового пространства текста / Е. Ю. Ильинова // Научный Вестник Воронежского государственного архитектурно-строительного университета. Серия «Современные лингвистические и методико-дидактические исследования». - 2006. -№ 6. - С. 9-17.

Качалкин, А. Н. Жанры русского документа допетровской эпохи : в 2 ч. / А. Н. Качалкин. - М. : МГУ, 1988. - Ч. І: Источники изучения и вопросы авторства документа. - 119 с. ; Ч. 2: Филологический метод анализа документа. -119 с.

Косова, М. В. Параметры речевого жанра как лингвистическая модель документа / М. В. Косова // Гуманитарные технологии в современном мире : материалы IV Всерос. науч.-практ. конф. с междунар. участием (Калининград, 22-24 мая 2015 г.) / сост. Л. М. Гончарова. -Калининград : [б. и.], 2015. - С. 73-75.

Косова, М. В. Системность как свойство документного текста / М. В. Косова // Вестник Волгоградского государственного университета. Серия 2, Языкознание. - 2012. - № 1 (15). - С. 7-11.

Краснова, О. Н. Композиционно-речевая реализация информативной функции в научном документе / О. Н. Краснова // Вестник Волгоградского государственного университета. Серия 2, Языкознание. - 2009. - № 1 (9). - С. 170-173.

Кузнецова, Т. В. Делопроизводство (документационное обеспечение управления) / Т. В. Кузнецова. М. : ЗАО Бизнес-Школа Интел-Синтез, 2002. - 374 с.

Кушнерук, С. П. Многокомпонентные единицы документных текстов (к проблеме судебных лингвистических экспертиз) / С. П. Кушнерук // Lingua mobilis. - 2010. - № 1 (20). - C. 75-82.

Ларин, М. В. Управление документацией в организациях / М. В. Ларин. - М. : Научная книга, 2001. $-288 \mathrm{c}$.

Ларьков, Н. С. Документоведение / Н. С. Ларьков. - М. : АСТ : Восток-Запад, 2006. - 430 с.

О гармонизации документов государственного стратегического планирования / А. В. Клименко, В. А. Королев, Д. Ю. Двинских, И. Ю. Сластихина. М. : Изд. дом Высш. шк. экономики, 2015. - 45 с.

Плигина, Е. С. К проблеме документного статуса PR-текста / Е. С. Плигина // Вестник Волгоградского государственного университета. Серия 2, Языкознание. - 2012. - № 2 (16). - С. 146-149.

Ромашова, О. В. Жанрово-стилевая специфика медицинского документа (на материале медицинской карты стационарного больного) / О. В. Рома- шова // Мир науки, культуры, образования. - 2014. № 5 (48)- С. 127-130.

Саидгасанова, Э. У. Договорная документация добровольческого объединения в коммуникативном аспекте / Э. У. Саидгасанова // Мир лингвистики и коммуникации. - 2014. - Вып. 3. - Электрон. текстовые дан. - Режим доступа : http://www. tverlingua.ru/. - Загл. с экрана.

Трофимова, О. В. Деловые тексты конца XVIII века из фондов государственного архива Тюменской области как лингвистический источник / О. В. Трофимова // Архив и исследователи: сотрудничество в интересах настоящего и будущего : материалы науч. конф., посвящ. 75-летию Гос. архива Тюмен. обл. (окт. 1997 г.). - Тюмень : Тюмен. гос. ун-т, 1997. - С. 38-40.

Трофимова, О. В. Опыт лингвопрагматического анализа регионального делового текста / О. В. Трофимова // Семантика и прагматика языковых единиц. Труды и материалы международной заочной научно-практической конференции. К 70-летию доцента Людмилы Семеновны Филипповой (Тюмень, 15-25 декабря 2011 г.). - Обнинск : Титул, 2013. C. $63-72$.

Шмелева, Т. В. Модель речевого жанра / Т. В. Шмелева // Жанры речи : сб. науч. ст. - Саратов : Изд-во ГосУНЦ «Колледж», 1997. - С. 88-98.

Шмелева, Т. В. Речевой жанр. Возможности описания и использования в преподавании языка / Т. В. Шмелева // Russistik. - 1990. - № 2. - С. 20-32.

\section{ИСТОЧНИКИ И СЛОВАРИ}

БТСРЯ - Большой толковый словарь русского языка / Гл. ред. С. А. Кузнецов. Российская Академия наук, Институт лингвистических исследований. - СПб. : Изд-во «Норинт», 2000. - 1536 с.

$M A C$ - Словарь русского языка : в 4 т. / Под ред. А. П. Евгеньевой. -2-е изд., испр. и доп. - Т. 2. М. : Русский язык, 1981-1984. - 736 с.

Стратегия РГО - Стратегия всероссийской общественной организации «Русское географическое общество» (утв. Управляющим советом Всероссийской общественной организации «Русское географическое общество», протокол заседания № 5 от 6 июля 2012 г.).

Федеральный закон от 28 июня 2014 г. № 172-Ф3 «О стратегическом планировании в Российской Федерации».

\section{REFERENCES}

Babenko L.G., Kazarin Yu.V. Lingvisticheskiy analiz khudozhestvennogo teksta. Teoriya i praktika 
[Linguistic Analysis of Fiction Text. Theory and Practice]. Moscow, Flinta: Nauka Publ., 2004. - 496 p.

Belokoneva K.A. K probleme zhanrovo-stilevoy prinadlezhnosti dokumentnogo teksta [To the Problem of Genre and Style of Document Text]. Vestnik Volgogradskogo gosudarstvennogo universiteta. Seriya 2, Yazykoznanie [Science Journal of Volgograd State University. Linguistics], 2011, no. 2 (14), pp. 148-153.

Galperin I.R. Tekst kak obyekt lingvisticheskogo issledovaniya [Text as an Object of Linguistic Study]. Moscow, Editorial URSS Publ., 2004. 144 p.

Gorban O.A., Ilyinova E.J., Kosova M.V., Sheptukhina E.M. Zhanrovye osobennosti vojskovyh gramot serediny XVIII v. (po materialam arhivnogo fonda «Mihajlovskij stanichnyj ataman») [Genre Characteristics of the 18th Century Military Charters (With Reference to the Mikhailovsky Stanitsa Ataman Archive)]. Izvestija Ural'skogo federal'nogo universiteta. Serija 2. Gumanitarnye nauki [IZVESTIA. Ural Federal University Journal. Series 2 Humanities and Arts], 2016, vol. 18, no. 4 (157), pp. 182199. DOI: 10.15826/izv2.2016.18.4.074

Ilynova E.Yu. Kognitivnyy aspekt zhanrovogo prostranstva teksta [Cognitive Aspect of Text's Genre Space]. Nauchnyy Vestnik Voronezhskogo gosudarstvennogo arkhitekturno-stroitelnogo universiteta. Seriya «Sovremennye lingvisticheskie $i$ metodiko-didakticheskie issledovaniya», 2006, vol. 6, pp. 9-17.

Kachalkin A.N. Zhanry russkogo dokumenta dopetrovskoy epokhi: $v 2$ ch. Ch. 2: Filologicheskiy metod analiza dokumenta [Genres of the Russian Document the Pre-Petrine Era. In 2 parts. Part 2: Linguistic Method of Analysis of the Document]. Moscow, MGU Publ., 1988. 119 p.

Kosova M.V. Parametry rechevogo zhanra kak lingvisticheskaya model dokumenta [Parameters of the Speech Genre as a Linguistic Model of Document]. Goncharov L.M., ed. Gumanitarnye tekhnologii v sovremennom mire: materialy IV Vseros. nauch.-prakt. konf. s mezhdunar. uchastiem (Kaliningrad, 2224 maya 2015 g.) [Humanities Technologies in the Modern World: Materials of the $4^{\text {th }}$ All-Russian Scientific-Practical Conference with International Participation (Kaliningrad, May 22-24, 2015)]. Kaliningrad, 2015, pp. 73-75.

Kosova M.V. Sistemnost kak svoystvo dokumentnogo teksta [Consistency as a Property of the Document Text]. Vestnik Volgogradskogo gosudarstvennogo universiteta. Seriya 2, Yazykoznanie [Science Journal of Volgograd State University. Linguistics], 2012, no. 1 (15), pp. 7-11.

Krasnova O.N. Kompozitsionno-rechevaya realizatsiya informativnoy funktsii $\mathrm{v}$ nauchnom dokumente [Compositional and Speech Implementation of Informative Functions in Academic Document]. Vestnik Volgogradskogo gosudarstvennogo universiteta. Seriya 2, Yazykoznanie [Science Journal of Volgograd State University. Linguistics], 2009, no. 1 (9), pp. 170-173.

Kuznetsova T.V. Deloproizvodstvo (dokumentatsionnoe obespechenie upravleniya) [Records' Management (Documentation Base of Management)]. Moscow, ZAO Biznes-Shkola IntelSintez, 2002. 374 p.

Kushneruk S.P. Mnogokomponentnye edinitsy dokumentnykh tekstov (k probleme sudebnykh lingvisticheskikh ekspertiz) [Multicomponent Units of Document Texts (the Problem of Judicial Linguistic Expertise)]. Lingua mobilis, 2010, no. 1(20), pp. 75-82.

Larin M.V. Upravlenie dokumentatsiey $v$ organizatsiyakh [Records' Management in Organizations]. Moscow, Nauchnaya kniga Publ., 2001. 288 p.

Larkov N.S. Dokumentovedenie [Documentation]. Moscow, AST: Vostok-Zapad, 2006. 430 p.

Klimenko A.V., Korolev V.A., Dvinskikh D.Yu., Slastikhina I.Yu. O garmonizatsii dokumentov gosudarstvennogo strategicheskogo planirovaniya [On Harmonization of the Documents of State Strategic Planning]. Moscow, Izd. dom Vyssh. shk. ekonomiki, 2015. 45 p.

Pligina E.S. K probleme dokumentnogo statusa PR-teksta [To the Problem of Document Status of PRText]. Vestnik Volgogradskogo gosudarstvennogo universiteta. Seriya 2, Yazykoznanie [Science Journal of Volgograd State University. Linguistics], 2012, no. 2 (16), pp. 146-149.

Romashova O.V. Zhanrovo-stilevaya spetsifika meditsinskogo dokumenta (na materiale meditsinskoy karty statsionarnogo bolnogo) [Genre-Stylistic Specificity of the Medical Document (Material of the Patient's Medical Card)]. Mir nauki, kultury, obrazovaniya [The World of Science, Culture, Education], 2014, no. 5 (48), pp. 127-130.

Saidgasanova E.U. Dogovornaya dokumentatsiya dobrovolcheskogo obyedineniya $\mathrm{v}$ kommunikativnom aspekte [Contract Documentation of Volunteer Association in Communicative Aspect]. Mir lingvistiki $i$ kommunikatsii [World of Linguistics and Communication], 2014, vol.3. URL: http://www.tverlingua.ru/.

Trofimova O.V. Delovye teksty kontsa XVIII veka iz fondov gosudarstvennogo arkhiva Tyumenskoy oblasti kak lingvisticheskiy istochnik [Business Texts of the Late $18^{\text {th }}$ Century from the Collections of the State Archive of the Tyumen Region as a Linguistic Source]. Arkhiv $i$ issledovateli: sotrudnichestvo $v$ interesakh nastoyashchego $i$ budushchego: materialy nauch. konf., posvyashch. 75-letiyu Gos. arkhiva Tyumen. obl. (okt. 1997 g.) [Archive and Researchers: Collaboration in the 


\section{МАТЕРИАЛЫ И СООБЩЕНИЯ}

Interests of the Present and the Future. Materials of Scientific Conference, Devoted to the $75^{\text {th }}$ Anniversary of the State Archive of the Tyumen Region (October, 1997)]. Tyumen, Tyumen. gos. un-t, 1997, pp. 38-40.

Trofimova O.V. Opyt lingvopragmaticheskogo analiza regionalnogo delovogo teksta [Experience of Linguopragmatic Analysis of Regional Business Text]. Semantika i pragmatika yazykovykh edinits. Trudy $i$ materialy mezhdunarodnoy zaochnoy nauchnoprakticheskoy konferentsii. K 70-letiyu dotsenta Lyudmily Semenovny Filippovoy (Tyumen, 15-25 dekabrya 2011 g.) [Semantics and Pragmatics of Language Units. The Works and Materials of International Extramural ScientificPractical Conference. To the $70^{\text {th }}$ Birthday of Professor Lyudmila S. Filippova (Tyumen, December15-25, 2011)]. Obninsk, Titul Publ., 2013,pp. 63-72.

Shmeleva T.V. Model rechevogo zhanra [Model of Speech Genre]. Zhanry rechi: sb. nauch. st. [Speech Genres: Collection of Scientific Works]. Saratov, Izdvo GosUNTs «Kolledzh», 1997, pp. 88-98.

Shmeleva T.V. Rechevoy zhanr. Vozmozhnosti opisaniya $\mathrm{i}$ ispolzovaniya $\mathrm{v}$ prepodavanii yazyka [Speech Genre. The Possibility of Describing and Using Language Teaching]. Russistik, 1990, no. 2, pp. 20-32.

\section{SOURCES AND DICTIONARIES}

Kuznetsov S.A., ed. Bolshoy tolkovyy slovar russkogo yazyka [Big explanatory dictionary of the Russian language]. Saint Petersburg, Izd-vo «Norint», 2000. 1536 p.

Evgenyeva A.P. Slovar russkogo yazyka: v 4 t. [Russian Dictionary: In 4 vols.]. Moscow, Russkiy yazyk Publ., 1981-1984. 736 p.

Strategiya vserossiyskoy obshchestvennoy organizatsii «Russkoe geograficheskoe obshchestvo» (utv. Upravlyayushchim sovetom Vserossiyskoy obshchestvennoy organizatsii «Russkoe geograficheskoe obshchestvo», protokol zasedaniya № 5 ot 6 iyulya 2012 g.) [Strategy of All-Russian Public Organization "Russian Geographical Society" (Approved by the Board of Directors of the All-Russian Public Organization "Russian Geographical Society", the Minutes of the Session no. 5 of July 6, 2012)].

Federalnyy zakon ot 28 iyunya 2014 g. № 172$F Z$ «O strategicheskom planirovanii v Rossiyskoy Federatsii» [The Federal Law of June 28, 2014 no. 172-FZ "On Strategic Planning in the Russian Federation"].

\section{Information about the Author}

Aleksandra S. Bystrova, Postgraduate Student, Department of Russian Philology, Volgograd State University, Prosp. Universitetsky, 100, 400062 Volgograd, Russian Federation, alexandra.kan@inbox.ru, http://orcid.org/0000-0002-2878-4359

\section{Сведения об авторе}

Александра Сергеевна Быстрова, аспирант кафедры русской филологии, Волгоградский государственный университет, просп. Университетский, 100, 400062 г. Волгоград, Российская Федерация, alexandra.kan@inbox.ru, http://orcid.org/0000-0002-2878-4359 